\title{
ANÁLISE DA ATIVIDADE DO PROFISSIONAL DE DESIGN ENVOLVIDO NA GESTÃO DE DESIGN
}

\section{DESIGN PROFESSIONAL ACTIVITY ANALYSIS IN DESIGN MANAGEMENT}

\author{
Cláudia de Souza Libânio*E-mail: clasl@terra.com.br \\ Fernando Gonçalves Amaral* E-mail: amaral@producao.ufrgs.br \\ *Universidade Federal do Rio Grande do Sul (UFRGS), Porto Alegre, RS
}

\begin{abstract}
Resumo: A percepção do uso do design como um elemento essencial para a obtenção de vantagem competitiva desperta nas empresas a necessidade de gerenciar também as atividades de design. Todavia, pouco se fala sobre a atividade dos profissionais de design participantes desse processo, seus papéis, funções e competências, e mesmo sobre suas ligações com a empresa e os demais setores envolvidos. O objetivo deste artigo é analisar, durante os processos de gestão de design, as relações de trabalho de profissionais de design vinculados interna e externamente às organizações, buscando compreender a estrutura e os fatores intervenientes na atividade desses profissionais, bem como as interações com seus principais interlocutores. A metodologia utilizada foi exploratória e qualitativa, através de entrevistas em profundidade com três profissionais de design. Posteriormente, foi feita uma análise das respostas, possibilitando a comparação desses dados obtidos com o referencial teórico pesquisado. Através deste estudo de caso, foi possível perceber o perfil e a atividade do profissional de design, bem as relações com seus principais interlocutores, quando vinculados interna e externamente às organizações.
\end{abstract}

Palavras-chave: Gestão de design. Profissional de design. Atividade de trabalho. Fatores intervenientes. Interlocutores.

\begin{abstract}
Design use perception, as an essential element for achieving competitive advantage, also suggests the need to manage the design activities in companies. However, a few is discussed about the activity of these design professionals who participate in this process, their roles, functions and competencies, including their connections to a company and other involved sectors. This article aims to analyze, during the design management processes, the work relations of design professionals connected to organizations both internal and externally, in order to comprehend the structure and intervenient factors on the activity of these professionals, as well as the interactions with their main coworkers. The methodology was exploratory and qualitative, using in-depth interviews with three design professionals. Subsequently, the responses were analyzed allowing the comparison of these obtained data to the theoretical bases researched. Through this case study, it was possible to realize the aspects and the structure of the design professional activity, connected intern and externally to organizations, as well as its relations with the main coworkers.
\end{abstract}

Key-words: Design management. Design professional. Work activities. Intervenient factors. Coworkers.

\section{INTRODUÇÃO}

Atualmente, é crescente o interesse na pesquisa do design relacionado à 
estratégia e à gestão nas empresas. Cada vez mais, o design é visto como uma atividade multidisciplinar, que interage com diversos níveis e estruturas nas organizações (BERTOLA; TEIXEIRA, 2002; CHIVA; ALEGRE, 2009; DELL'ERA; VERGANTI, 2010; RAVASI; STIGLIANI, 2012), sendo tema de debates e estudos relacionados à gestão de design (LIBÂNIO; AMARAL, 2011). Segundo Cardoso e Kistmann (2008), a partir de uma perspectiva estratégica, o design pode ser percebido como uma das competências centrais das companhias. Entretanto, de acordo com Libânio e Amaral (2011), pouco se pesquisa sobre os agentes, setores e profissionais de design envolvidos nesse processo, quem são seus interlocutores e quais são suas atribuições, funções e competências.

O profissional de design é o responsável pelo entendimento, pela ocorrência e pelo incentivo dessas ações integradas e multidisciplinares. Borja de Mozota (2003) defende que a gestão de design tem dois objetivos: formar parceiros-gerentes e designers, e desenvolver métodos para integrar o design nas organizações. Kotler e Rath (1984) enfatizam que os designers devem participar de todas as etapas de desenvolvimento dos produtos, interagindo com as áreas envolvidas em determinado projeto. Avendaño (2003) também destaca a integração dos diversos agentes participantes da gestão de design e defende a importância da participação ativa dos envolvidos nas decisões dos produtos.

\subsection{A Gestão de Design}

De acordo com Borja de Mozota (2003), a gestão de design surgiu na década de 1960, na Grã-Bretanha. A autora destaca que, em 1975, foi fundado o Design Management Institute (DMI), um consagrado instituto que, até a atualidade, é referência em pesquisas sobre o tema. Desde então, conceitos são propostos na tentativa de estruturar e formalizar uma definição que englobe e sistematize os fatores e as ações dos indivíduos envolvidos da gestão de design. O quadro 1 apresenta algumas das principais definições de gestão de design, organizadas cronologicamente. Para este estudo, adota-se o conceito de Borja de Mozota (2003), que define a gestão de design como a implantação do design como um programa formal de atividades na organização, comunicando sua relevância para os objetivos 
de longo prazo da companhia, com a função de coordenar os seus recursos em todos os níveis da atividade corporativa, buscando atingir os objetivos da empresa.

Quadro 1 - Definições sobre Gestão de Design

\begin{tabular}{|c|c|c|}
\hline Conceitos de Gestão de Design & $\begin{array}{l}\text { Autor/Insti- } \\
\text { tuições }\end{array}$ & Ano \\
\hline $\begin{array}{l}\text { Coordenar, integrar e articular todos os fatores que, de alguma maneira, } \\
\text { participam do processo construtivo da forma do produto. Com isso, } \\
\text { estamos nos referindo tanto ao uso, consumo individual ou social do } \\
\text { produto (fatores funcionais, simbólicos ou culturais), como aos que se } \\
\text { referem à produção (fatores técnico-econômicos, técnico-construtivos, } \\
\text { técnico-sistemáticos, técnico-produtivos e técnico-distributivos). }\end{array}$ & $\begin{array}{l}\text { International } \\
\text { Council of } \\
\text { Societies of } \\
\text { Industrial Design } \\
\text { (ICSID), Tomas } \\
\text { Maldonado }\end{array}$ & 1977 \\
\hline $\begin{array}{l}\text { É o emprego efetivo dos recursos de design disponíveis numa } \\
\text { organização, de acordo com seus objetivos estratégicos. }\end{array}$ & Peter Gorb & 1990 \\
\hline $\begin{array}{l}\text { Em nível de projeto, a gestão de design ocupar-se-á de gerir os recursos } \\
\text { humanos e materiais, desde a concepção até o lançamento do produto no } \\
\text { mercado. Em nível amplo, a gestão de design procura criar uma } \\
\text { organização e um clima favoráveis ao nascimento de novos produtos, } \\
\text { proporcionando-lhes as condições e os meios adequados. }\end{array}$ & $\begin{array}{l}\text { Centro } \\
\text { Português de } \\
\text { Design (CPD) }\end{array}$ & 1997 \\
\hline $\begin{array}{l}\text { E a organização e coordenação de todas as atividades de design, com } \\
\text { base nos objetivos definidos pela empresa. }\end{array}$ & Brigite Wolf & 1998 \\
\hline $\begin{array}{l}\text { É a implantação do design como um programa formal de atividades na } \\
\text { organização, comunicando sua relevância para os objetivos de longo } \\
\text { prazo da companhia, com a função de coordenar os seus recursos em } \\
\text { todos os níveis da atividade corporativa, buscando atingir os objetivos da } \\
\text { empresa. }\end{array}$ & $\begin{array}{l}\text { Brigite Borja de } \\
\text { Mozota }\end{array}$ & 2003 \\
\hline $\begin{array}{l}\text { Consiste na necessidade de condicionar os recursos e métodos, } \\
\text { organizando o ambiente para torná-lo propício ao surgimento de novos } \\
\text { produtos. }\end{array}$ & $\begin{array}{l}\text { Spoladore e } \\
\text { Demarchi }\end{array}$ & 2004 \\
\hline $\begin{array}{l}\text { Conjunto de atividades de diagnóstico, coordenação, negociação e } \\
\text { design, que pode ser desenvolvida tanto na atividade de consultoria } \\
\text { externa como no âmbito da organização, interagindo com os setores } \\
\text { responsáveis pela produção, programação econômico-financeira e e } \\
\text { comercialização, permitindo sua participação ativa nas decisões dos } \\
\text { produtos. }\end{array}$ & Luis Avendaño & 2005 \\
\hline $\begin{array}{l}\text { É uma tarefa de liderança, que necessita ser demonstrada como um ativo } \\
\text { positivo para a organização, auxiliando no alcance de suas metas. }\end{array}$ & Kathryn Best & 2006 \\
\hline $\begin{array}{l}\text { É a atividade total do design, sua administração e contribuição para o } \\
\text { desempenho de uma empresa. Inclui também a organização e a } \\
\text { implementação do processo para desenvolver novos produtos e serviços. }\end{array}$ & Design Council & 2008 \\
\hline $\begin{array}{l}\text { Gestão de design abrange os processos em curso, as decisões de } \\
\text { negócios e estratégias que permitam a inovação e a criação de design } \\
\text { efetivo em produtos, serviços, comunicações, ambientes e marcas que } \\
\text { melhorem nossa qualidade de vida e proporcionem o sucesso } \\
\text { organizacional. Visa unir design, inovação, tecnologia, gestão e clientes } \\
\text { para oferecer vantagens competitivas através de três linhas-base: } \\
\text { econômica, social/cultural e fatores ambientais. É a arte e a ciência para a } \\
\text { capacitação do design, promovendo a colaboração e a sinergia entre } \\
\text { "design" e "negócios". }\end{array}$ & $\begin{array}{l}\text { Design } \\
\text { Management } \\
\text { Institute (DMI) }\end{array}$ & 2010 \\
\hline
\end{tabular}

Fonte: Elaborado pelo autor. 


\subsection{Profissionais de Design}

De acordo com a estrutura das empresas, podem ser destacados os profissionais de design envolvidos na gestão de design, tais como: o gestor de design elou gestor de projetos de design, o designer e até mesmo técnicos em design. Segundo Pereira (2009), o processo de criação de produtos, tangíveis e intangíveis, é uma das responsabilidades do gestor de design. O autor destaca ainda que, nas organizações de grande porte, esse gestor deve supervisionar as equipes envolvidas em cada projeto, tendo uma visão sobre a abrangência do negócio e integrando as unidades operacionais no contexto da estratégia global da empresa. Já nas empresas de pequeno porte, o autor afirma que, apesar da inexistência de unidades operacionais a supervisionar, o gestor de design deve agir de forma a conduzir o processo de projetos de maneira integrada com os objetivos da empresa.

O gestor de design deve alinhar seu posicionamento e suas ações às diretrizes, aos objetivos e às estratégias da empresa. Segundo Gallina (2006), para que o objetivo estratégico da empresa seja atingido, são fundamentais também o engajamento e a dedicação de seus colaboradores. Avendaño (2002) salienta que o gestor de design deve gerenciar processos aliados a conhecimentos de gestão, empreendedorismo, visão de negócios, competitividade, liderança aliada ao espírito de equipe; conhecimentos da cadeia produtiva e ciclo de vida do produto; inovação, qualidade, entre outros. Para Avendaño (2002), a função do gestor de design em uma empresa é a implantação de políticas e estratégias de design, tornando competitivos seus produtos e sua imagem perante o mercado. Para o autor, sua função tem caráter estratégico, possibilitando a inserção da cultura do design na filosofia e nos objetivos da empresa, reportando-se diretamente à direção da companhia. Borja de Mozota (2003) complementa que o trabalho do gestor de design engloba a gestão da criatividade, a gestão de pessoal e a gestão financeira da empresa.

No que tange ao papel do designer, Borja de Mozota (2003) afirma que este deve ser tanto um especialista quanto um integrador, pois deve construir rotinas que sejam integradoras e aperfeiçoar as ferramentas de inovação, incentivando que esse processo seja contínuo e dinâmico nas empresas. De acordo com o Conselho 
Nacional de Educação (2003), o designer deve ser um profissional apto para a produção de projetos, os quais envolvam sistemas de informações visuais, artísticas, estéticas, culturais e tecnológicas, observados o ajustamento histórico, os traços culturais e de desenvolvimento das comunidades e as características dos usuários e de seu contexto sócio-econômico e cultural. Complementa ainda que o designer também deve ter a capacidade de interagir com profissionais de outras áreas, utilizando conhecimentos diversos e atuando em equipes interdisciplinares na elaboração e na execução de pesquisas e projetos. Dias Júnior (2006) destaca que o designer deve, sobretudo, ser um agente solucionador de demandas externas, interagindo também com outros subsistemas locais. Avendaño (2002) destaca que o designer tem um perfil altamente criativo e inovativo, com capacidade de gerenciamento de materiais e dados tecnológicos, sendo responsável pela criação de produtos novos. As principais disciplinas de design e meios de atuação e interface do designer nas empresas, segundo Borja de Mozota (2003), são as de design de produto, design de embalagem, design gráfico, design de ambientes e design para a internet.

Além do designer e do gestor de design, Avendaño (2002) ainda indica outro profissional relacionado à gestão de design: o técnico em design. O autor explica que esse profissional tem a cultura do design, mas não cria produtos, atua somente em nível técnico, é um profundo conhecedor do "chão de fábrica" e dos processos industriais e põe em prática a visão do designer nas linhas de produção. Todos esses profissionais, desde o gestor de design até o técnico em design, devem realizar suas atividades de maneira integrada, interagindo com os demais setores e interlocutores envolvidos em projetos de design. Tanto os profissionais em design quanto os seus interlocutores podem estar vinculados diretamente às empresas (agentes internos), ou ser prestadores de serviços esporádicos às empresas (agentes externos).

\subsection{Agentes de Design Internos e Externos ás Empresas}

Tratando-se de um departamento interno de design, as vantagens elencadas por Borja de Mozota (2003) são: eficiência de custo; confiabilidade e proteção das 
ideias da companhia; otimização e padronização dos processos; acessibilidade; fácil coordenação; controle maior pela empresa; design com uma melhor compreensão dos padrões e características da organização. A autora ainda lista as desvantagens: limitações na criatividade, apatia do designer por limitações na gama dos produtos ou serviços, possível aumento de despesas se comparados ao design externo, sobrecarga de trabalho na equipe interna e a perda de contato com ideias e desenvolvimentos externos. O Centro Português de Design - CPD (1997) acrescenta que a contratação de designers para o quadro deve ocorrer junto às mudanças na atribuição de responsabilidades e na organização do desenvolvimento de produtos novos.

Com relação às vantagens de a organização optar por um design externo (terceirização), Borja de Mozota (2003) elenca: a possibilidade de nova inspiração; o acesso à expertise de especialistas; menor sobrecarga de trabalho interno; o acesso a pessoas e a habilidades extras; assim como possibilidades de mudanças e descobertas de novas e diferentes opções. Ainda segundo a autora, as desvantagens são as seguintes: a falta de entendimento de questões particulares da empresa; dificuldades de acesso ao cotidiano da empresa; problemas de coordenação entre a equipe de design e demais áreas; baixa confiabilidade nos projetos; empresa necessita de habilidades para avaliar questões de design; síndrome do "não foi inventado aqui"; problemas de implementação na estrutura produtiva da empresa do design criado externamente; perda da continuidade e do controle da relação; e falta de credibilidade do design desenvolvido externamente, caso esteja fora do estilo da companhia. Best (2006) destaca que, para haver a contratação de uma equipe externa de design, devem ser avaliados alguns aspectos, como se essa equipe irá proporcionar um retorno sobre o investimento feito e qual o valor desses ativos de projeto. A autora sugere que um caminho menos oneroso seria contratar agências menores especializadas; entretanto, algumas empresas adotam equipes mistas (design externo e design interno), para não ficarem tão limitadas a uma equipe de design.

Borja de Mozota (2003) afirma que uma solução mais adequada seria o design como um departamento da empresa, mas independente de sua estrutura. A autora destaca que essa alternativa é a mais usualmente utilizada pelos diretores 
que consideram o design como uma área estratégica. A autora ainda salienta que, dessa forma, o departamento de design está diretamente ligado à administração geral, participando logo no início do projeto de concepção de produtos e orientando políticas de design de longo prazo da empresa. Corroborando essa ideia, Neumeier (2010) defende que, ao estruturar um departamento interno de design, a companhia reproduza internamente uma pequena agência de design. O autor entende que, com essa ação, as demais áreas da empresa teriam um maior respeito pela equipe interna de design.

Diante do exposto, este artigo tem como objetivo apresentar uma análise das relações de trabalho de profissionais de design vinculados interna e externamente às organizações, buscando compreender a estrutura e os fatores intervenientes da atividade desses profissionais e suas interações com seus principais interlocutores.

\section{PROCEDIMENTOS METODOLÓGICOS}

A metodologia utilizada neste trabalho foi exploratória, de pesquisa qualitativa, com entrevistas em profundidade (MALHOTRA, 2001). Malhotra (2001) destaca que a pesquisa qualitativa é uma metodologia de pesquisa não-estruturada e exploratória, possibilitando a compreensão do problema. Com relação ao estudo de caso, Gil (1999) afirma que se caracteriza por um estudo profundo e detalhado de um ou mais objetos, de maneira que possibilite um conhecimento abrangente e minucioso - tarefa praticamente irrealizável a partir de outras formas de delineamentos. Yin (2001) também salienta que o estudo de caso é utilizado como estratégia de pesquisa quando perguntas do tipo "como" e "por que" são colocadas, quando o pesquisador não controla os eventos e quando o foco da pesquisa está em fenômenos contemporâneos.

Foi elaborado um questionário semiestruturado para aplicação nas entrevistas realizadas com três profissionais de design. Os dados foram obtidos por meio de fontes primárias, sendo utilizada uma abordagem direta nas entrevistas. Anteriormente, esses profissionais estavam vinculados a empresas desenvolvedoras de produtos ou prestadoras de serviços, fazendo parte de suas equipes de design. Posteriormente, esses profissionais se desvincularam das organizações, abrindo seu 
próprio escritório de design e passando a prestar serviços para as empresas, sendo contratados por projeto.

Para garantir o anonimato dos três entrevistados, eles estão identificados como Entrevistado 1 (E1), Entrevistado 2 (E2) e Entrevistado 3 (E3). O E1 trabalhou inicialmente na empresa $A$, uma metalúrgica que produz acessórios em metal para os setores de decoração e da moda. Posteriormente, abriu seu próprio escritório (empresa B), prestando serviços para empresas desenvolvedoras de produto e prestadoras de serviço. O E1 tem mais de 16 anos de experiência na área de design e sinalização, sendo 13 desses trabalhando internamente na empresa A. Através da empresa $B$, o $E 1$ oferece como serviços: pesquisa de novas possibilidades de produtos e oportunidades; desenvolvimento de produtos; criação e análise do plano de marketing e assessoramento na criação e no posicionamento de marca e identidade visual. Conta com uma equipe de cinco profissionais internos e outros consultores terceirizados. A empresa B situa-se em um parque tecnológico, como empresa incubada.

O E2 trabalhou inicialmente na empresa $C$, uma metalúrgica produtora de acessórios em metal para os setores de decoração e da moda. Após sua saída da companhia, o E2 abriu seu próprio escritório (empresa D), prestando serviços tanto para empresas desenvolvedoras de produto quanto para prestadoras de serviço. $O$ E2 tem mais de 12 anos de experiência na área de design e sinalização, sendo 6 desses trabalhando internamente na empresa $C$. A empresa $D$ tem dois profissionais internos e conta também com prestadores de serviços terceirizados, e oferece serviços nas áreas de design de produto, gráfico e web, além de análise do posicionamento de marca e definição de estratégias organizacionais relacionadas ao design.

O E3 tem mais de 22 anos de experiência na área de design e sinalização, sendo 14 desses trabalhando internamente em um escritório de grande porte (empresa E). Com sua saída desse escritório, no ano de 2009, fundou, juntamente com dois sócios, o seu próprio escritório (empresa F), especializado em sinalização, arquitetura, comunicação visual e design para ambientes. A empresa $F$ conta com seis profissionais internos e alguns prestadores de serviço terceirizados. Todos os três entrevistados (E1, E2 e E3) têm formação em Desenho Industrial, no Brasil. 
Para a análise dos resultados, foi utilizada a classificação de Ruas et al. (2005), que divide as competências em atitudes, habilidade e conhecimentos. As atividades desses profissionais, bem como suas relações e interações, foram analisadas em dois momentos distintos: primeiramente, quando faziam parte da equipe interna de design de organizações (empresa A, empresa C e empresa E) e, posteriormente, trabalhando em seus próprios escritórios de design (empresa $\mathrm{B}$, empresa D e empresa F), prestando serviços para as outras empresas. Foram identificados pontos relevantes de análise na atividade e nas relações desses profissionais nos dois momentos estudados. Com isso, foi possível analisar as atividades dos profissionais de design vinculados interna e externamente às organizações, buscando a compreensão da estrutura e dos fatores intervenientes nas relações desses profissionais e suas interações com seus interlocutores.

\section{RESULTADOS}

Os aspectos analisados foram organizados e classificados em quatro grandes grupos: situação (perfil) das empresas, o profissional de design, as interações entre setores e atividades e atuação do profissional de design como agente externo às empresas. Esses quatro grupos foram subdivididos em itens julgados relevantes para análise, conforme segue.

\subsection{Situação (ou Perfil) das Empresas A, B, C, D, E, F}

A empresa A tem 32 anos de existência e possui como negócio a produção de metais, atendendo o mercado calçadista, da moda e de decoração. Já a empresa $B$ foi criada há um ano e dois meses e seu negócio é auxiliar as empresas a crescerem através do design e do marketing. Seu foco de atuação é na cadeia calçadista, cadeia de decoração e serviços. Fundada há 25 anos, a empresa C desenvolve acessórios inovadores em metal, tendo como mercado o calçadista, da moda e da decoração. A empresa $D$ é um escritório de design de produto com foco na gestão de design e no design thinking como método de trabalho e atua prestando serviços para indústrias da região da serra do Estado do Rio Grande do Sul, como 
indústrias moveleiras, de metal-mecânico e de acessórios para banho. Atuando no mercado há 27 anos, a empresa $E$ presta serviços para indústria, comércio e serviços, tendo como negócio a utilização do design para criação e gestão de marcas. Com um ano de existência, a empresa $F$ atua na construção de identidade para as organizações, através de projetos que contribuam para a experiência, a acessibilidade e o bem-estar das pessoas em qualquer espaço. A empresa $F$ presta serviços para: varejo, serviços, corporativos, escolas, saúde, transportes, indústria, restaurantes, hotéis, cidades, parques, vias, espaços culturais e residenciais.

Fazem parte da equipe de design da empresa $A$ : um profissional com graduação e pós-graduação em design, um profissional com graduação em design, três estudantes com graduação em andamento em design e oito profissionais com curso técnico em mecânica. Já na empresa $B$, integram a equipe de design: um profissional com graduação e pós-graduação em design (sócio-diretor), um profissional com graduação em design e três profissionais de nível médio. A equipe ainda conta com o auxílio de consultores com titulação de mestre para prestação de serviços de forma terceirizada. A equipe de design da empresa C conta com um tecnólogo em moda e estilo com pós-graduação em design e um profissional com graduação, pós-graduação e mestrado em design. A empresa D conta com dois funcionários: um com graduação em andamento em design e outro com graduação, pós-graduação e mestrado em design (sócio-diretor). Por ser uma prestadora de serviços em design, a empresa $\mathrm{E}$ conta com seis equipes de design, divididas por segmento de atuação. A pesquisa foi feita em uma dessas equipes composta de seis funcionários, sendo: dois com graduação em arquitetura, dois com graduação em design e dois com graduação e pós-graduação em design. Já a equipe de design da empresa F é composta de: um designer gráfico com pós-graduação em design (sócio-diretor), um administrador de empresas pós-graduado em marketing (sóciodiretor), um arquiteto pós-graduado em luminotécnica (gerente de projetos), um arquiteto pós-graduado em design e MBA em marketing (sócio-diretor) e dois designers.

A empresa $A$, inicialmente, buscava informações para a criação de novos produtos através de benchmark e, posteriormente, já com uma equipe estruturada de design, iniciou um trabalho de pesquisas de megatendências. Com essa nova 
percepção do design, acabou acrescentando a palavra design ao seu nome. O E1 salienta que o design e o planejamento estratégico andam juntos na empresa $A$, porém, inicia no design e depois vai para a estratégia. A empresa B utiliza o processo inverso, ou seja, a estratégia conduz o design. O E1 destaca que a análise mercadológica, o comportamento de consumo, a criação de painéis conceituais e a avaliação de concorrência são métodos de busca de informações para a proposição de novos produtos e serviços da empresa B.

O E2 salienta que o grau de aderência do design da empresa C é relativo, pois, apesar de o design ter grande importância para a gestão da empresa C, a equipe de design tinha algumas deficiências e limitações de entendimento, competências e autonomia. A procura por informações para novos produtos e serviços é feita através de pesquisas de mercado, busca por informações sobre concorrentes e fornecedores no mercado, acompanhamento de feiras internacionais e tendências mundiais. Esses mesmos métodos também são utilizados pela empresa D para a proposição de novos produtos e serviços; entretanto, na empresa $D$, o design é entendido como um método que pode beneficiar todos os setores da companhia na resolução de problemas, não somente no desenvolvimento de novos produtos. O E2 afirma que existe um expressivo grau de aderência do design pela empresa $D$ e que o design este faz parte do planejamento estratégico da empresa.

Com relação à empresa $E$, ela utiliza a pesquisa de mercado e tendências como ponto de partida para a conceituação e a concepção de produtos e serviços novos. A empresa $F$ faz uso desses procedimentos, mas também acompanha os lançamentos da concorrência. O E3 argumenta que as empresas E e $F$ se assemelham bastante em alguns pontos: em ambas, o design faz parte do planejamento estratégico da empresa, com total grau de adesão ao design. O E3 destaca ainda que, para a empresa F, o ambiente é, em particular, ponto de atenção, pois ela entende que o design pode identificar, direcionar, comunicar e educar, proporcionando conforto e representando aumento de produtividade nas companhias.

No que tange a mensuração de desempenho, percebe-se que as empresas não detém um conjunto estruturado de medidas que desempenho. Somente as empresas $B, C$ e $E$ ressaltam que utilizam alguns indicadores bem como normas ISO 
para medir o desempenho de seus produtos no mercado. De acordo com Fonseca e Rozenfeld (2012), não basta um somente ter um conjunto de medidas de desempenho para o sucesso da organização. Os autores ressaltam que dois pontos fundamentais para este processo de medição: a definição de padrões que serão utilizados para avaliar a realização dos objetivos da organização e a frequência desta medição. O Quadro 2 elenca outros dados relevantes das empresas analisadas no estudo.

\subsection{O Profissional de Design}

O E1 destaca que atuou na empresa $A$, durante 13 anos, como gerente de design, sendo responsável por todo o desenvolvimento de produtos. Atualmente, na empresa $\mathrm{B}$, o $\mathrm{E} 1$ atua há um ano como sócio-diretor, propondo ideias diferenciadas e inovadoras, visando lucro para as empresas contratantes. Enquanto a empresa A desenvolve metais para calçados, a empresa B tem como propósito auxiliar as companhias a crescerem através do design e do marketing. O E2 ocupava o cargo de analista técnico na empresa $\mathrm{C}$ e, atualmente, atua como sócio-designer na empresa D. Na empresa C, O E2 era responsável pelo atendimento e pelo desenvolvimento de produtos para a linha de decoração, tanto para as coleções da empresa quanto para clientes específicos. No entanto, na empresa D ele atua em todas as funções, desde prospecção e contato com clientes até desenvolvimento de produtos, coordenação e supervisão de equipe e projetos, apresentações e reuniões com os clientes, negociações com fornecedores, profissionais terceirizados e departamentos das contratantes, bem como realiza funções de marketing, financeiro e compras. Já o E3 ocupava o cargo de coordenador do núcleo de projetos de sinalização e comunicação visual na empresa $E$ e, atualmente, é sócio-diretor da empresa $F$, a qual é prestadora de serviços nas áreas corporativas, de varejo, serviços e promocionais.

Na empresa E, o E3 era responsável pela coordenação e liderança de um núcleo de projetos, envolvendo-se mais na parte estratégica do que na operacional. Hoje em dia, porque a empresa $F$ dispõe de uma estrutura mais enxuta, o E3 tem atribuições nos níveis estratégico e tático, como o atendimento e prospecção a 
clientes, a coordenação e supervisão de projetos, funções de marketing e, por vezes, contatos diretos com departamentos das empresas contratantes.

Quadro 2 - Outros dados relevantes na análise das empresas A, B, C, D, E, F.

\section{Empresa A Empresa B Empresa C Empresa D Empresa E Empresa F}

\begin{tabular}{|c|c|c|c|c|c|c|}
\hline $\begin{array}{l}\text { Conflitos nas } \\
\text { equipes de } \\
\text { design }\end{array}$ & raramente & não & $\operatorname{sim}$ & não & raramente & não \\
\hline $\begin{array}{l}\text { Terceirização } \\
\text { de trabalhos } \\
\text { com agentes } \\
\text { externos }\end{array}$ & $\begin{array}{l}\text { nos níveis } \\
\text { tático e } \\
\text { operacional }\end{array}$ & $\begin{array}{c}\text { no nível } \\
\text { operacional }\end{array}$ & não & $\begin{array}{c}\text { no nível } \\
\text { operacional }\end{array}$ & $\begin{array}{c}\text { no nível } \\
\text { operacional }\end{array}$ & $\begin{array}{c}\text { no nível } \\
\text { operacional }\end{array}$ \\
\hline $\begin{array}{l}\text { Plano de } \\
\text { cargos e } \\
\text { salários }\end{array}$ & não & $\operatorname{sim}$ & $\operatorname{sim}$ & não & sim & não \\
\hline $\begin{array}{l}\text { Plano de } \\
\text { carreira }\end{array}$ & não & $\operatorname{sim}$ & não & não & sim & não \\
\hline $\begin{array}{l}\text { Prêmios e } \\
\text { recompensas } \\
\text { aos } \\
\text { profissionais }\end{array}$ & $\operatorname{sim}$ & $\operatorname{sim}$ & não & não & não & não \\
\hline $\begin{array}{l}\text { Incentivos de } \\
\text { treinamento e } \\
\text { desenvolvi- } \\
\text { mento dos } \\
\text { funcionários }\end{array}$ & $\operatorname{sim}$ & $\operatorname{sim}$ & $\operatorname{sim}$ & $\operatorname{sim}$ & $\operatorname{sim}$ & $\operatorname{sim}$ \\
\hline $\begin{array}{l}\text { Mensuração } \\
\text { de } \\
\text { desempenho }\end{array}$ & não & $\begin{array}{l}\text { sim, através } \\
\text { de contrato } \\
\text { de risco }\end{array}$ & $\begin{array}{l}\text { sim, } \\
\text { através de } \\
\text { normas } \\
\text { ISO e } \\
\text { indicadores }\end{array}$ & não & $\begin{array}{l}\text { sim, através } \\
\text { de } \\
\text { indicadores }\end{array}$ & não \\
\hline Turnover & sim & não & não & não & $\operatorname{sim}$ & não \\
\hline $\begin{array}{l}\text { Requisitos } \\
\text { para integrar } \\
\text { a equipe de } \\
\text { design }\end{array}$ & $\begin{array}{l}\text { capacidade } \\
\text { técnica }\end{array}$ & $\begin{array}{c}\text { pró- } \\
\text { atividade, } \\
\text { conheciment } \\
\text { o acadêmico }\end{array}$ & $\begin{array}{l}\text { Graduação } \\
\text { em curso: } \\
\text { design ou } \\
\text { moda }\end{array}$ & $\begin{array}{l}\text { Formação: } \\
\text { design. Área } \\
\text { complementa } \\
\text { r engenharia }\end{array}$ & $\begin{array}{l}\text { conheciment } \\
\text { o técnico, } \\
\text { formação, } \\
\text { bom portfólio }\end{array}$ & $\begin{array}{c}\text { conheciment } \\
\text { o na área e } \\
\text { pró- } \\
\text { atividade }\end{array}$ \\
\hline
\end{tabular}

Fonte: Elaborado pelo autor

Com relação ao grau de subordinação, o E1 e o E3 afirmam que, nas empresas $\mathrm{A}$ e $\mathrm{E}$, respectivamente, eles se reportavam diretamente à direção (e/ou sócios). Já o E2 estava subordinado ao responsável pelo setor de design da empresa $\mathrm{C}$, e esse funcionário reportava-se diretamente à direção. Os três entrevistados saíram de empresas que dispõem de uma grande estrutura, a fim de criar suas próprias empresas, que têm estruturas menores. Entretanto, a relação entre a estrutura e o grau de subordinação é inversamente proporcional, ou seja, os 
entrevistados saíram de empresas (A, C, E) com grandes estruturas, onde tinham um grau de subordinação relativo, para criarem suas próprias empresas (B, D, F), onde existe autonomia. Os E1 e E2 não possuem sócios, e o E3 tem dois sócios, com quem divide responsabilidades e com quem toma decisões em conjunto. Entretanto, o E3 destaca que tem autonomia total nas suas atividades e decisões da empresa F.

Quanto às competências necessárias para desempenhar a função, foram selecionadas as três subdivisões propostas por Ruas et al. (2005): habilidades, atitudes e conhecimentos. No quesito habilidades, o E1 enfatiza que, na empresa A, era demandado adequar o que o cliente desejava à realidade da fábrica, enquanto que, na empresa $\mathrm{B}$, fez-se necessário ajustar a nova proposta à realidade do cliente. Já o E2 destaca o ato de projetar como habilidade exigida na empresa B. Com relação à empresa $\mathrm{D}$, o E2 lista as seguintes habilidades: projetar estratégias de produtos, negociação, capacidade de percepção de situações de projeto e identificação de oportunidades no mercado. O E3 elenca como habilidades para atuação nas empresas E e F uma comunicação e gestão acertadas.

As atitudes atribuídas como competências necessárias para o desempenho da atividade do E1, na empresa $A$, eram a tenacidade e o entusiasmo, e, na empresa $B$, a pró-atividade e a iniciativa em solucionar problemas. O E2 destaca a persistência como atitude requerida na empresa C e o empreendedorismo na empresa D. Para o E3, o comprometimento é tido como atitude primordial para a empresa E, e, para a empresa F, a pró-atividade aliada ao comprometimento. O E1 acredita que os conhecimentos das diversas culturas mundiais são aspectos essenciais para a empresa $A$. No entanto, os conhecimentos requeridos pela empresa B são relativos a sistemas de inovação, de acordo com ele. Já o E2 afirma que o design era o conhecimento primordial para a sua atividade na empresa $\mathrm{C}$, e, para a empresa $\mathrm{D}$, acrescenta ao design os conhecimentos relacionados a design thinking, gestão e administração. Para o E3, conhecimentos técnicos e de mercado merecem destaque no desempenho das atividades de design das empresas $\mathrm{E}$ e $\mathrm{F}$.

O Quadro 3 ilustra as competências requeridas pelas empresas e mencionadas pelos entrevistados. 


\begin{tabular}{|c|c|c|c|c|c|c|}
\hline \multirow[t]{3}{*}{ Quadro 3} & \multirow{2}{*}{\multicolumn{2}{|c|}{$\begin{array}{l}\text { Competências requeridas } \\
\text { entrevistados } \\
\begin{array}{|c|}\text { E1 }\end{array}\end{array}$}} & \multicolumn{4}{|c|}{ pelas empresas e mencionadas pelos profissionais } \\
\hline & & & & & \multicolumn{2}{|c|}{ E3 } \\
\hline & \multicolumn{2}{|c|}{ Empresa } & \multicolumn{2}{|c|}{$\begin{array}{l}\text { E2 } \\
\text { Empresa }\end{array}$} & Emp & resa \\
\hline $\begin{array}{l}\text { Competência } \\
\text { s }\end{array}$ & A & B & C & D & E & $\mathbf{F}$ \\
\hline Habilidades & $\begin{array}{l}\text { Adequar o } \\
\text { que o } \\
\text { cliente } \\
\text { deseja à } \\
\text { realidade } \\
\text { da fábrica }\end{array}$ & $\begin{array}{l}\text { Adequar a } \\
\text { nova } \\
\text { proposta à } \\
\text { realidade } \\
\text { do cliente }\end{array}$ & de projeto & $\begin{array}{l}\text { Projetar } \\
\text { estratégias de } \\
\text { produtos, } \\
\text { negociação, } \\
\text { capacidade de } \\
\text { identificar } \\
\text { oportunidades } \\
\text { de projeto e no } \\
\text { mercado }\end{array}$ & $\begin{array}{l}\text { Comunica- } \\
\text { ção e } \\
\text { gestão }\end{array}$ & $\begin{array}{l}\text { Comunica- } \\
\text { ção, gestão, } \\
\text { pensamento } \\
\text { estratégico }\end{array}$ \\
\hline Atitudes & $\begin{array}{l}\text { Tenacidade } \\
\text { e } \\
\text { entusiasmo }\end{array}$ & $\begin{array}{l}\text { Pró- } \\
\text { atividade, } \\
\text { resolução } \\
\text { de } \\
\text { problemas }\end{array}$ & $\begin{array}{l}\text { Persistên- } \\
\text { cia }\end{array}$ & $\begin{array}{l}\text { Empreendedo- } \\
\text { ra }\end{array}$ & $\begin{array}{l}\text { Comprome- } \\
\text { timento }\end{array}$ & $\begin{array}{l}\text { Comprome- } \\
\text { timento e } \\
\text { pró- } \\
\text { atividade }\end{array}$ \\
\hline $\begin{array}{l}\text { Conhecimen- } \\
\text { tos }\end{array}$ & $\begin{array}{l}\text { De diversas } \\
\text { culturas }\end{array}$ & $\begin{array}{l}\text { Sistemas } \\
\text { de } \\
\text { inovação }\end{array}$ & $\begin{array}{l}\text { Técnico } \\
\text { de design }\end{array}$ & $\begin{array}{l}\text { Técnicos: } \\
\text { design, design } \\
\text { thinking, } \\
\text { gestão e } \\
\text { administração }\end{array}$ & $\begin{array}{l}\text { De mercado } \\
\text { e técnico }\end{array}$ & $\begin{array}{l}\text { De mercado } \\
\text { e técnico }\end{array}$ \\
\hline
\end{tabular}

Fonte: Elaborado pelo autor.

No que tange à existência de um gestor de projetos de design atuante, o E1 entende que desempenhava essa função tanto na empresa $A$ quanto na empresa $B$. O E2, no entanto, entende que essa função é desempenhada atualmente na empresa $D$, mas, na empresa $C$, ele acredita que em nenhum momento existiu a figura de um gestor de design ou de um gestor de projetos de design. O E2 afirma que existia um responsável pelo setor, mas que esse não desempenhava funções de gestão, somente exercia uma liderança intimidadora e burocrática. Segundo o E3, a função do gestor de design existe tanto na empresa $E$ quanto na $F$.

O Quadro 4 ilustra os perfis e as atividades dos designers entrevistados nas empresas em questão. 
Quadro 4 - Comparação dos perfis e atividades dos designers nas empresas.

\begin{tabular}{|c|c|c|c|c|c|c|}
\hline & \multirow{2}{*}{\multicolumn{2}{|c|}{ E1 }} & \multirow{2}{*}{\multicolumn{2}{|c|}{ E2 }} & \multirow{2}{*}{\multicolumn{2}{|c|}{ E3 }} \\
\hline & & & & & & \\
\hline & \multicolumn{2}{|c|}{ Empresa } & \multicolumn{2}{|c|}{ Empresa } & \multicolumn{2}{|c|}{ Empresa } \\
\hline & A & B & C & D & E & $F$ \\
\hline $\begin{array}{l}\text { Cargo } \\
\text { ocupado }\end{array}$ & $\begin{array}{l}\text { Gerente de } \\
\text { design }\end{array}$ & Sócio-diretor & $\begin{array}{l}\text { Analista } \\
\text { técnico de } \\
\text { design }\end{array}$ & $\begin{array}{l}\text { Sócio- } \\
\text { designer }\end{array}$ & $\begin{array}{l}\text { Coordena- } \\
\text { dor do } \\
\text { núcleo de } \\
\text { projetos de } \\
\text { sinalização } \\
\text { e } \\
\text { comunica- } \\
\text { ção visual }\end{array}$ & $\begin{array}{l}\text { Sócio- } \\
\text { diretor }\end{array}$ \\
\hline \multirow{2}{*}{$\begin{array}{l}\text { Tempo de } \\
\text { experiência } \\
\text { nas } \\
\text { empresas } \\
\text { pesquisadas }\end{array}$} & 13 anos & Um ano & Seis anos & Um ano & 14 anos & Um ano \\
\hline & \multicolumn{2}{|c|}{ Total: 14 anos } & \multicolumn{2}{|c|}{ Total: 7 anos } & \multicolumn{2}{|c|}{ Total: 15 anos } \\
\hline Atribuições & $\begin{array}{l}\text { Desenvolvi- } \\
\text { mento de } \\
\text { produtos da } \\
\text { empresa }\end{array}$ & \begin{tabular}{|l|} 
Coordena- \\
ção de \\
projetos, \\
prospecção \\
e contato \\
com clientes, \\
marketing, \\
financeiro, \\
compras; \\
contato com \\
terceiriza- \\
dos, fornece- \\
dores e de- \\
partamentos \\
das \\
contratantes
\end{tabular} & $\begin{array}{l}\text { Atendimen- } \\
\text { to e desen- } \\
\text { volvimento } \\
\text { de produtos } \\
\text { para a linha } \\
\text { de } \\
\text { decoração } \\
\text { (coleções } \\
\text { da empresa } \\
\text { e clientes } \\
\text { específicos) }\end{array}$ & \begin{tabular}{|l} 
Coordenação \\
de projetos, \\
desenvolvi- \\
mento de \\
produtos, \\
prospecção e \\
contato com \\
clientes, \\
marketing, \\
financeiro, \\
compras, \\
contato com \\
terceirizados, \\
fornecedores \\
e departa- \\
mentos das \\
contratantes \\
\end{tabular} & $\begin{array}{l}\text { Coordena- } \\
\text { ção de } \\
\text { projetos, } \\
\text { liderança } \\
\text { de } \\
\text { equipes, } \\
\text { contato } \\
\text { com } \\
\text { clientes }\end{array}$ & $\begin{array}{l}\text { Coordena- } \\
\text { ção de } \\
\text { projetos, } \\
\text { pros- } \\
\text { peç̧ão e } \\
\text { contato } \\
\text { com } \\
\text { clientes, } \\
\text { marketing } \\
\text { e contato } \\
\text { com } \\
\text { departa- } \\
\text { mentos } \\
\text { das } \\
\text { contratan- } \\
\text { tes }\end{array}$ \\
\hline $\begin{array}{l}\text { Subordina- } \\
\text { ção }\end{array}$ & $\begin{array}{l}\text { Aos sócios } \\
\text { da empresa }\end{array}$ & Não há & $\begin{array}{l}\text { Responsá- } \\
\text { vel pelo se- } \\
\text { tor de } \\
\text { design }\end{array}$ & Não há & $\begin{array}{l}\text { Ao diretor } \\
\text { geral da } \\
\text { empresa }\end{array}$ & $\begin{array}{l}\text { Sociedade } \\
\text { com dois } \\
\text { sócios }\end{array}$ \\
\hline $\begin{array}{l}\text { Interações } \\
\text { da equipe } \\
\text { de design } \\
\text { com áreas } \\
\text { envolvidas } \\
\text { no projeto }\end{array}$ & Sim & Sim & $\begin{array}{l}\text { Frequente- } \\
\text { mente }\end{array}$ & Sim & $\begin{array}{l}\text { Frequente- } \\
\text { mente }\end{array}$ & Sim \\
\hline Autonomia & Não & Sim & $\begin{array}{l}\text { Até certo } \\
\text { ponto }\end{array}$ & Sim & $\begin{array}{l}\text { Até certo } \\
\text { ponto }\end{array}$ & Sim \\
\hline $\begin{array}{l}\text { Existência } \\
\text { de gestor de } \\
\text { design }\end{array}$ & Sim & Sim & Não & Sim & Sim & Sim \\
\hline
\end{tabular}

Fonte: Elaborado pelo autor 


\subsection{Interações entre Setores e Atividades}

No que tange às interações entre departamentos e colegas de trabalho, o E1 destaca que, nos primeiros anos de atividades na empresa $A$, teve que estimular a integração entre as equipes de trabalho envolvidas nos projetos. Ele acredita que esse foi um dos aspectos que contribuíram para o crescimento da empresa A. O E2 salienta que, na empresa $\mathrm{C}$, interagiam no desenvolvimento de produtos as seguintes áreas: comercial, design, matrizaria, produção, direção e vendas. Os departamentos de marketing e engenharia não participam do desenvolvimento de produtos na empresa $\mathrm{C}$ pela total inexistência desses setores. Já o E3 defende que a interação acontece entre as equipes de projeto, os prestadores de serviços terceirizados, o atendimento e a direção da empresa $\mathrm{E}$, bem como com setores da contratante envolvidos em um projeto. Todavia, os entrevistados E1, E2 e E3 entendem que a integração nas empresas $B, D$ e $F$, respectivamente, são maiores pelas estruturas mais enxutas e também pelo maior comprometimento. Por vezes, entretanto, devido a essa estrutura enxuta, os profissionais integrantes das equipes de design das empresas $B, D$ e $F$ acumulam diversas funções que não somente as de design. O E1 ainda acrescenta que o sentimento de propriedade da organização desperta maior empenho, dedicação e responsabilidade. Os três entrevistados (E1, E2 e E3) classificam como muito boa a interação e o relacionamento da equipe de design com a alta direção da empresa.

Já o compartilhamento de informações e conhecimentos entre profissionais e setores envolvidos em determinado projeto não acontece de maneira frequente nas empresas A, C e E. Isso se deve, em parte, às estruturas organizacionais e, por vezes, à excessiva divisão de equipes e atividades com funções rígidas e específicas das companhias. Como resultado, encontram-se equipes trabalhando de maneira isolada, sem grande troca de informações com setores participantes de um projeto. Já as empresas B, D e F, por terem estruturas internas menores, dialogam e trocam informações de maneira mais constante e frequente.

Os três entrevistados (E1, E2 e E3) afirmam existir contato direto dos designers com os clientes. Todavia, os entrevistados E1 e E3 salientam que, nas empresas em que trabalharam, existiam também os agentes que faziam contato com 
os clientes, através de multiplicadores, na empresa A, e do atendimento, na empresa E. Com relação às áreas envolvidas, bem como seus interlocutores, no desenvolvimento de produtos e serviços, os entrevistados E1, E2 e E3 destacaram os setores conforme o Quadro 4. Para melhor compreensão do Quadro 5, salientase que a palavra 'não' refere-se a setores existentes nas empresas mas que não interagem com os demais setores, enquanto que a palavra 'inexistente' refere-se a setores que não existem nas empresas estudadas.

Quadro 5 - Comparação da ocorrência de interações entre setores e atividades.

\begin{tabular}{|l|c|c|c|c|c|c|}
\cline { 2 - 7 } \multicolumn{1}{c|}{} & \multicolumn{7}{c}{ Empresa } \\
\cline { 2 - 7 } Direção & A & B & C & D & E & F \\
\cline { 2 - 7 } Marketing & $\operatorname{sim}$ & $\operatorname{sim}$ & $\operatorname{sim}$ & $\operatorname{sim}$ & sim & sim \\
\hline Engenharia & raramen-te & inexiste & inexiste & inexiste & inexiste & inexiste \\
\hline $\begin{array}{l}\text { Comercial/ } \\
\text { Atendimento }\end{array}$ & inexiste & inexiste & inexiste & inexiste & inexiste & inexiste \\
\hline Vendas & sim & sim & sim & inexiste & sim & sim \\
\hline Financeiro & não & inexiste & sim & inexiste & inexiste & inexiste \\
\hline Design & não & inexiste & não & inexiste & não & inexiste \\
\hline Produção e Matrizaria & sim & sim & sim & sim & sim & sim \\
\hline Clientes & sim & inexiste & sim & inexiste & inexiste & inexiste \\
\hline $\begin{array}{l}\text { Profissionais } \\
\text { Terceirizados }\end{array}$ & raramen-te & sim & inexiste & sim & sim & sim \\
\hline
\end{tabular}

Fonte: Elaborado pelo autor.

\subsection{Profissional de Design como Agente Externo às Empresas}

Apesar de a interação interna entre os funcionários das empresas $B, D$ e $F$ ocorrer de maneira efetiva e constante, percebe-se que a interação entre essas empresas (contratadas) e os funcionários das empresas contratantes não ocorre com a mesma eficiência como acontece internamente. O compartilhamento de informações das empresas $B, D$ e $F$ com as contratantes também fica comprometido. Isso acontece em função do distanciamento e, por vezes, da falta de uma maior interação com setores que se envolvem em um projeto, mas que não são percebidos como fonte relevante de informação.

Outro fator relevante da pesquisa refere-se aos profissionais e/ou setores com que os entrevistados (E1, E2 e E3) têm contato nas empresas contratantes. O E1 destaca que seus contatos diretos são, geralmente, com donos das empresas, 
gerentes de projeto e/ou gerentes de marketing, conforme a demanda da empresa. Já o E2 afirma que seu trabalho, em grande parte, é a terceirização do setor de projetos para as empresas contratantes e que, às vezes, chega a fazer parte da equipe por um tempo pré-determinado. Seus contatos ocorrem com os seguintes setores: direção, vendas, marketing, engenharia, custos, compras, qualidade e design (conforme a existência desses setores nas empresas). O E3 elenca os setores de projetos, direção e terceirizados da empresa contratante como as áreas nas quais ocorre maior interação e troca de informações. Contudo, os três entrevistados destacam que, tanto na relação interna das empresas $A, B, C, D, E$ e $F$, quanto no relacionamento com as empresas $B, D$ e $F$ existe um bom relacionamento entre a direção e os profissionais das equipes de design. Quando questionados sobre a existência de departamentos ou profissionais de design nas empresas contratantes, os entrevistados (E1, E2 e E3), em sua totalidade, responderam que, por vezes, existem esses departamentos e profissionais. O E1 acrescenta ainda que ele é contratado para atuar em conjunto com esses profissionais das empresas contratantes, agregando valor com ideias novas.

Os entrevistados também foram questionados sobre o entendimento deles em relação à figura de um designer à frente da empresa. O E1 salienta que, nessa situação, o desprendimento é maior e, por consequência, a decisão racional fica mais facilitada. Do ponto de vista do E2, isso é essencial, pois ele acredita que o designer tem uma visão ampla das etapas de projeto e dos negócios. O E2 ainda afirma que o designer deve, num futuro próximo, fazer parte de todos os processos das empresas, indo além do desenvolvimento de novos produtos. Ainda com relação a essa questão, a autonomia e o entendimento mais claro do design na alta direção da empresa são fatores a serem considerados, segundo o E3. O Quadro 6 evidencia os pontos fortes e fracos do trabalho dos profissionais de design como agentes internos e externos às empresas, segundo respostas dos entrevistados E1, E2 e E3. 
Quadro 6 - Pontos fortes e fracos do trabalho dos profissionais de design como agentes internos e externos às empresas.

\begin{tabular}{|c|c|c|c|}
\hline & & \\
\hline & & Pontos Fortes & Pontos Fracos \\
\hline \multirow{2}{*}{ E1 } & Empresa A & Estabilidade e segurança. & $\begin{array}{l}\text { Visão de design limitada ao universo } \\
\text { interno da empresa. }\end{array}$ \\
\hline & Empresa B & $\begin{array}{l}\text { Mercado crescente, desafios, visão } \\
\text { generalista de várias realidades. }\end{array}$ & Marca não é conhecida pelo mercado. \\
\hline \multirow[b]{2}{*}{ E2 } & Empresa C & Estabilidade. & $\begin{array}{l}\text { Empresa acomodada, falta de liberdade } \\
\text { para criação e falta de incentivos na busca } \\
\text { de novas ideias. }\end{array}$ \\
\hline & Empresa D & $\begin{array}{l}\text { Envolvimentos em projetos, } \\
\text { mercados e gestões mais } \\
\text { desafiadoras e com maior liberdade } \\
\text { para criação. }\end{array}$ & $\begin{array}{l}\text { Ainda está se estruturando, crescendo e } \\
\text { se posicionando no mercado. }\end{array}$ \\
\hline \multirow{2}{*}{ E3 } & Empresa E & $\begin{array}{l}\text { Empresa já conhecida e consagrada } \\
\text { no mercado. }\end{array}$ & Estrutura grande e autonomia limitada. \\
\hline & Empresa F & $\begin{array}{l}\text { Ganho de reconhecimento de seu } \\
\text { trabalho no mercado. }\end{array}$ & $\begin{array}{l}\text { Empresa iniciante, ainda prospectando } \\
\text { clientes e se posicionando no mercado. }\end{array}$ \\
\hline
\end{tabular}

Fonte: Elaborado pelo autor.

\section{DISCUSSÃO}

A importância da integração das equipes de design com as demais áreas e interlocutores participantes da gestão de design é percebida pelos entrevistados como fator-chave e elemento essencial no desenvolvimento de produtos e serviços e na busca de valor agregado e de diferencial competitivo no mercado, indo ao encontro das afirmações de Borja de Mozota (2003). Perks, Cooper e Jones (2005) ressaltam ainda a importância e a efetividade do trabalho destas equipes multifuncionais. Todavia, nota-se uma maior integração dos profissionais de design com alguns setores/áreas envolvidos em determinado projeto quando vinculados internamente às organizações. Quando na condição de prestadores de serviço externos às empresas, os profissionais de design interagem com áreas que eles julgam ser as mais relevantes/atuantes no projeto ou com os profissionais que lhes são apresentados como interlocutores pela empresa contratante. Em grande parte das vezes, os entrevistados mencionaram que o principal contato das empresas $B, D$ e F com as contratantes ocorre com a direção ou com os donos das empresas. 
Todavia, um prestador de serviços, externo a uma organização, precisa compreender como ocorrem os processos de desenvolvimento de produtos e prestação de serviços na empresa, como os departamentos interagem e quais são os objetivos e as diretrizes da corporação antes de iniciar qualquer tipo de atividade. Esses procedimentos encontram subsídios nas afirmações de Kotler e Rath (1984), que defendem a integração de todas as áreas envolvidas em determinado projeto, assim como a participação dos designers ao longo de todas as etapas de desenvolvimento de produtos, ou seja, desde definição de diretrizes estratégicas, desenvolvimento e produção dos produtos/serviços até o lançamento e acompanhamento de desempenho desses produtos/serviços no mercado.

Entende-se que a integração de equipes e o desenvolvimento de atividades multidisciplinares incentivam a formação de parceiros de trabalho que compartilham informações e que trabalham de maneira integrada. Borja de Mozota (2003) destaca a importância da formação de parceiros-gerentes e designers e da integração do design no ambiente organizacional. Quando designers externos prestam serviços para empresas contratantes, deveriam incentivar o trabalho multidisciplinar entre as áreas envolvidas, mostrando a importância desse comportamento para os diretores das empresas. Por vezes, a alta direção da empresa não percebe a relevância da integração de certas equipes e profissionais para o bom andamento dos projetos. Durante os 13 anos em que trabalhou na empresa A, o E1 destacou, como um aspecto determinante para o crescimento da organização, o estímulo à integração entre as equipes de trabalho envolvidas nos projetos. De acordo com Libânio e Amaral (2011), essa integração deve ocorrer não somente entre a direção ou o gerente de projetos, mas entre todas as áreas envolvidas em determinado projeto na organização. A equipe de design deve atuar com interlocutores como, por exemplo: o setor financeiro (para acompanhar os custos de um novo investimento), o marketing (para alinhar o posicionamento e o lançamento de um produto no mercado), a produção e matrizaria (desenvolvendo ajustes e adaptações nos produtos, com intuito de aumentar a produtividade e reduzir custos), a direção da empresa (alinhando os projetos ao negócio e objetivos das empresas) e até mesmo os clientes (entendendo suas reais necessidades e expectativas). Tais relações são salientadas por Gorb (1990), sustentando que a gestão de design visa a empregar, 
de maneira efetiva, os recursos de design disponíveis em uma organização, de acordo com os objetivos estratégicos da companhia. Isso é corroborado por Borja de Mozota (2003), ao salientar que a gestão de design busca atingir os objetivos das empresas.

Um fator interveniente, destacado como um ponto fraco pelos entrevistados, quando eram funcionários internos das empresas $A, C$ e E, foi a limitação de autonomia e a falta de liberdade tanto para a realização de seus trabalhos quanto para as definições de projetos. Acredita-se que outro fator interveniente, e que dificulta a integração de todos os envolvidos em um projeto, é a localização física. Nesse caso, prestadores de serviços externos que não incentivam ou que não são incentivados a integrarem-se ao ambiente e às atividades das equipes das contratantes envolvidas em determinado projeto ainda têm a distância como um agravante. O E2 destaca que, atuando na empresa D, por vezes, ele trabalha dentro da estrutura física da empresa contratante, fazendo parte da equipe de design, tentando, assim, minimizar esse fator interveniente.

Os entrevistados têm formação em design e destacam a importância da presença de um designer na alta direção da empresa, argumentando que o designer possui um entendimento mais claro das etapas de projeto e da compreensão do design inserido na gestão de design. Indo ao encontro da visão de Libânio (2011), entende-se, que o designer pode atuar de maneira conjunta com os demais envolvidos na alta direção da empresa, fazendo parte da alta diretoria em empresas de grande porte e relacionando-se de maneira direta com a alta direção em empresas de pequeno porte com estruturas mais enxutas. Com isso, incentiva-se a integração e a troca de conhecimentos de gestores com designers, com competências requeridas e autonomia para tomada de decisões. Nesse contexto, segundo Kotler e Rath (1984), profissionais de marketing devem adquirir um melhor entendimento dos processos de design e designers, bem como uma melhor compreensão dos processos de marketing. As empresas devem estimular designers a atuarem em ambiente empresarial em igualdade com colegas administradores, evidenciando o valor do design para os profissionais ligados à área da gestão.

Outro aspecto relevante pesquisado relaciona-se às competências dos profissionais das equipes de design. De acordo com Ruas et al. (2005), toda a 
competência é fundamentada em um conjunto de capacidades, relacionando-se diretamente ao conhecimento, às habilidades e às atitudes do indivíduo envolvido em determinado processo. Tais atitudes foram observadas e elencadas como primordiais pelo E1: tenacidade, entusiasmo (para a empresa A) e pró-atividade e iniciativa para solucionar problemas (para a empresa $B$ ), também corroborando o pensamento de Nedo apud Bruce et al. (1999) acerca das competências para designers. Já o E2 entende como habilidades relevantes aquelas relacionadas à estratégia (projetar estratégias de produtos, capacidade de identificar oportunidades de projeto e de mercado) e as aptidões comerciais (negociação), as quais se coadunam com a classificação de habilidades feita por Borja de Mozota (2003). Nessa classificação, as habilidades descritas por E2, relacionadas à habilidade estratégica, são competências de design em sistemas, e as relacionadas às aptidões empresariais são entendidas como competências de design voltadas para a orientação empresarial. No quesito conhecimento, tanto o E2 quanto o E3 destacaram os conhecimentos técnicos e científicos como competências relevantes para os profissionais de design, corroborando o pensamento de Borja de Mozota (2003) e Nedo apud Bruce et al. (1999) acerca das competências em design.

\section{CONCLUSÃO}

Este estudo objetivou evidenciar como ocorrem as relações de trabalho de profissionais de design vinculados interna e externamente às organizações, buscando a compreensão da estrutura e dos fatores intervenientes da atividade desses profissionais, bem como as interações com seus principais interlocutores. Com base no conjunto de informações coletadas, pôde-se concluir que a integração das equipes envolvidas em um projeto deve ser estimulada tanto pelos profissionais envolvidos em projetos quanto pela alta direção da empresa. Embora os entrevistados reconheçam a importância da integração das equipes de design com as demais áreas e interlocutores participantes da gestão de design, por vezes, esta integração não evidenciou-se na prática, o que fragiliza uma efetiva atividade multidisciplinar.

No momento em que profissionais externos às empresas são requeridos para 
alguma atividade, estes devem integrar-se às demais equipes da empresa contratante, buscando a troca de informações e atuando de maneira efetiva e conjunta nos projetos. Espera-se que, com a prestação de serviços externos, ideias novas, proposições inovadoras e um novo olhar sobre as movimentações do mercado venham a agregar valor e expertise aos produtos, serviços e posicionamento das empresas contratantes. Entretanto, esses profissionais que vêm de fora da organização devem ter, de acordo com Borja de Mozota (2003), a compreensão dos padrões e das características da organização. Dependendo da estrutura da organização, a criação de uma equipe mista de design (com profissionais de design internos e externos às empresas) pode ser uma proposta integradora, possibilitando o contato com novas ideias, referências e tendências (através dos profissionais de design externos), mas também detendo o controle, a padronização dos processos e as características da empresa em seus produtos e serviços. Já os interlocutores da equipe de design serão os que estiverem envolvidos em determinado projeto. Áreas como marketing, produção, matrizaria, comercial, financeiro, engenharia, direção e demais profissionais (externos ou internos), envolvidos direta e indiretamente nos projetos, são peças-chave e que detêm informações e conhecimentos relevantes, os quais devem ser compartilhados constantemente.

Com relação aos profissionais trabalhando internamente nas empresas, ficou evidenciado que a autonomia fica comprometida pelas relações de poder hierárquico na organização. Porém, no que concerne à integração e à troca de informações, essas são beneficiadas pela maior presença temporal e pela proximidade física com os outros interlocutores e as demais equipes envolvidas.

Vale destacar que a alta direção da empresa necessita de profissionais de design que tenham competências em design, além das requeridas para a gestão, para agir de maneira estratégica na gerência de uma organização. Com isso, as equipes de design reportar-se-ão aos gestores de design inseridos na alta administração, ou a gestores de projetos de design, de acordo com o tamanho da estrutura da organização. Consequentemente, o design adquirirá maior importância e inserção nos níveis organizacionais. Além disso, os profissionais de design serão incentivados e terão maior autonomia para propor ideias novas no desenvolvimento 
de produtos e serviços.

Portanto, espera-se que os designers ou profissionais de design com competências em design possam atuar em conjunto com gestores, diretores e demais interlocutores dos projetos, incentivando o trabalho integrado entre as equipes. Sendo assim, o design tende a adquirir força nas empresas, permeando os níveis estratégico, tático e operacional nas organizações.

A pesquisa de campo realizada tem como limitação a aplicação em uma amostra pequena, localizada e não probabilística, não sendo possível a aplicação dos resultados e conclusões deste estudo nas empresas e profissionais de design em geral. Em virtude da grande variedade de estruturas empresariais e setores de atuação, fica a sugestão para próximas pesquisas de estudos em setores específicos de mercado e/ou em determinadas estruturas organizacionais.

\section{REFERÊNCIAS}

AVENDAÑO, L. E. C. Resgate do protagonismo do desenhista industrial através da gestão do design. In: CONGRESSO INTERNACIONAL DE PESQUISA EM DESIGN, 5,. 2002, Rio de Janeiro. Anais... Rio de Janeiro, 2002.

AVENDAÑO, L. E. C. Interação designer/empresa no contexto estratégico do desenvolvimento do produto. Dissertação (Mestrado). Universidade de São Paulo, São Paulo, SP, 2003.

AVENDAÑO, L. E. C. Resgate do protagonismo do desenhista industrial por meio da gestão do design. Revista do Programa de Pós-Graduação em Arquitetura e Urbanismo da FAUUSP/USP, São Paulo: USP, 2005.

BERTOLA, P.; TEIXEIRA, J.C. Design as a knowledge agent: how design as a knowledge process is embedded into organizations to foster innovation. Design Studies, v.24, n.2, 2003.

BEST, K. Design management: managing design strategy, process and implementation. Switzerland: Ava, 2006.

BORJA DE MOZOTA, B. Design Management: Using Design to Build Brand Value and Corporate Innovation. New York: Allworth, 2003.

BRUCE, M.; COOPER, R.; VAZQUEZ, D. Effective design management for small businesses. Design Studies, v. 20, 1999.

\section{CARDONETTI, V. K. Princípios norteadores para a implementação e avaliação}


da gestão de design nas MPES do setor industrial de vestiário. Dissertação (Mestrado). Universidade Federal de Santa Catarina, Florianópolis, SC, 2009.

CARDOSO, M.A.; KISTMANN, V.B. Modularização e design na indústria automotiva: o caso do modelo Fox da Volkswagen do Brasil. Revista Produção Online, Florianópolis, v.8, n.4, 2008.

CHIVA, R.; ALEGRE, J. Investment in design and firm performance: the mediating role of design management. The Journal of Product Innovation Management. v.26, 2009.

CONSELHO NACIONAL DE EDUCAÇÃO. Parecer CNE/CES nº. 0195/2003, de 05 de agosto de 2003. Diretrizes Curriculares Nacionais dos cursos de graduação em Música, Dança, Teatro e Design. Relatores: José Carlos Almeida da Silva e Lauro Ribas Zimmer. Diário Oficial da União, Brasília, 12 de fevereiro de 2004. Seção 1 , p. 14. Disponível em: < http://portal.mec.gov.br/cne/arquivos/pdf/CES_0195.pdf>. Acesso em: set. 2010.

CPD - Centro Português de Design. Manual de gestão do design. Porto: Centro de Diseño, 1997.

DESIGN COUNCIL. Disponível em: < www.designcouncil.org.uk >. Acesso em: 26 out. 2010.

DELL'ERA, C.; VERGANTI, R. Collaborative Strategies in design-intensive industries knowledge diversity and innovation. Long Range Planning v.43, p. 123-141, 2010.

DIAS JÚNIOR, C.M. Perspectivas para a adequação de competências na formação do designer baseadas numa proposta pedagógica de desenvolvimento sócioeconômico. Revista Produção Online, Florianópolis, v.6, n.3, p.40, set./dez, 2006.

DMI - Design Management Institute. Disponível em: <www.dmi.org>. Acesso em: 05 nov. 2010.

FONSECA, F.E.A.; ROZENFELD, H. Medição de desempenho para a gestão do ciclo de vida de produtos: uma revisão sistemática da literatura. Revista Produção

Online. Florianópolis, SC, v.12, n. 1, p. 159-184, jan./mar. 2012.

GALLINA, M. C. Ações do líder na gestão design como auxílio na formação do branding: um estudo de caso em uma empresa do setor do mobiliário. Dissertação (Mestrado). Universidade Federal do Paraná, Curitiba, 2006.

GIL, A. C. Métodos e técnicas de pesquisa social. 5. ed. São Paulo: Atlas, 1999.

GORB, P. Design management. New York: Van Nostrand Reinhold, 1990.

KOTLER, P.; RATH, G. A. Design: a powerful but neglected strategic tool. Journal of Business Strategy, 1984. 
LIBÂNIO, C.L. O profissional de design e suas interfaces na gestão de design: um estudo de caso. Dissertação (Mestrado). Universidade Federal do Rio Grande do Sul, Porto Alegre, RS, 2011.

LIBÂNIO, C.S.; AMARAL, F.G. Aspectos da gestão de design abordados em dissertações e teses no Brasil: uma revisão sistemática. Revista Produção Online, Florianópolis, SC, v.11, n. 2, p. 565-594, abr./jun., 2011.

MALDONADO, T. El diseño industrial reconsiderado. Barcelona, Espanha: Gustavo Gili,. 1977.

MALHOTRA, N. Pesquisa de marketing, uma orientação aplicada. 3. ed. Porto Alegre: Bookman, 2001.

NEUMEIER, M. A empresa orientada pelo design. Porto Alegre: Bookman, 2010.

PEREIRA, D. Competências da gestão estratégica do design no polo moveleiro do Alto Vale do Rio Negro (SC). Dissertação (Mestrado). Universidade Tecnológica Federal do Paraná, Ponta Grossa, PR, 2009.

PERKS, H.; COOPER, R.; JONES, C. Characterizing the role of design in new product development an empirically derived taxonomy. The Journal of Product Innovation Management, v.22, p.11-127, 2005.

POWELL, E. N. Developing a framework for design management. Design Management Journal. sum., 1998.

RAVASI, D.; STIGLIANI, I. Product design: a review and research agenda for management studies. International Journal of Management Reviews, 2012.

RUAS, R. L.; ANTONELLO, C. S.; BOFF, L. H. Os novos horizontes da gestão: aprendizagem organizacional e competências. Porto Alegre: Bookman, 2005.

SPOLADORE, R., DEMARCHI, A. A gestão do design no desenvolvimento de produtos na Indústria Digital. In: P\&D DESIGN, 2004, São Paulo. Anais... São Paulo, 2004.

WOLF, B. O Design Management como fator de sucesso comercial.

Florianópolis: IEL; ABIPTI; Programa Catarinense de Design; SEBRAE, 1998.

YIN, R. K. Estudo de caso: planejamento e métodos. 2.ed. Porto Alegre: Bookman, 2001.

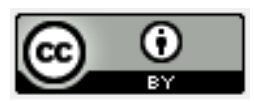

Artigo recebido em 31/07/2011 e aceito para publicação em 14/06/2013. 


\section{APÊNDICE - ROTEIRO PARA ENTREVISTA}

\section{Quanto às empresas}

1. Qual o mercado atendido pela empresa?

EMPRESA ANTERIOR:

EMPRESA ATUAL:

2. Qual o negócio da empresa?

EMPRESA ANTERIOR:

EMPRESA ATUAL:

3. Quantos anos tem a empresa?

EMPRESA ANTERIOR:

EMPRESA ATUAL:

4. Como acontece a busca por informações para o lançamento de novos produtos? (Pesquisa de mercado, de concorrência...)

EMPRESA ANTERIOR:

EMPRESA ATUAL:

5. Quem são (e quem eram, na época) os integrantes da equipe de design da empresa? Quais as formações (nível superior, com pós, mestrado...)?

EMPRESA ANTERIOR:

EMPRESA ATUAL:

6. Como o design é (era) visto pela empresa? Existe (existia) alguma diferença de visão entre as duas empresas?

EMPRESA ANTERIOR:

EMPRESA ATUAL: produtos?

7. Como ocorre (ocorria) a demanda por novos projetos/lançamento de novos

EMPRESA ANTERIOR:

EMPRESA ATUAL:

8. Existiam processos de trabalho formalizados e estruturados na organização ou ocorre um processo informal de trabalho?

EMPRESA ANTERIOR:

EMPRESA ATUAL: qual?

9. Existe (existiu) algum conflito interno na equipe de design? Caso positivo,

EMPRESA ANTERIOR:

EMPRESA ATUAL:

10. O design faz parte do planejamento estratégico da empresa?

EMPRESA ANTERIOR:

EMPRESA ATUAL:

11. Existe (existia) alguma terceirização de trabalho ou todo o processo acontece (acontecia) dentro da empresa?

EMPRESA ANTERIOR:

EMPRESA ATUAL:

12. Quem são os concorrentes diretos da empresa?

EMPRESA ANTERIOR:

EMPRESA ATUAL:

Revista Produção Online, Florianópolis, SC, v.13, n. 3, p. 843-872, jul./set. 2013. 


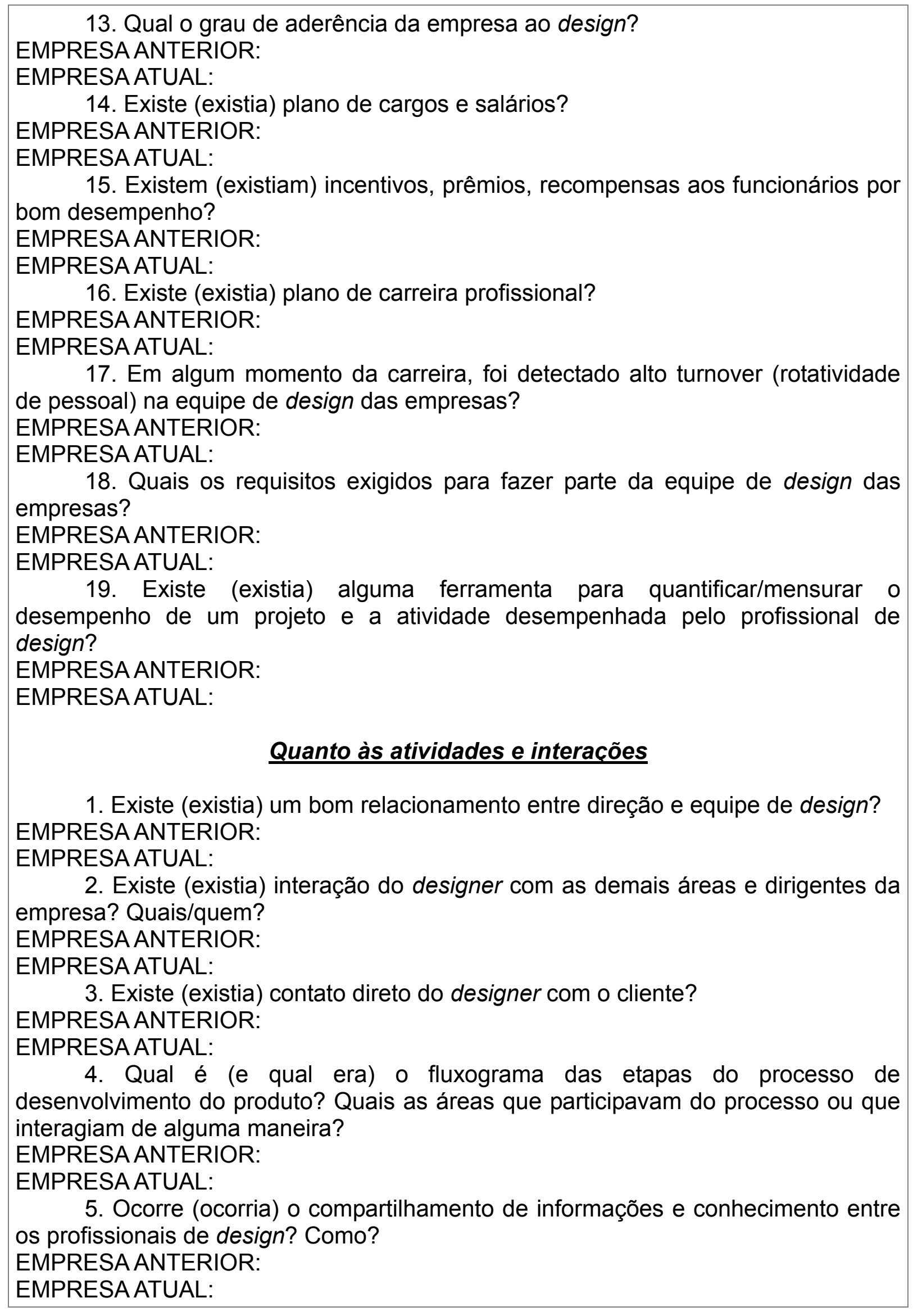




\section{Quanto ao profissional de Design}

1. Qual o seu cargo?

EMPRESA ANTERIOR:

EMPRESA ATUAL:

2. Por quantos anos trabalhou na empresa anterior?

3. Quais as suas atribuições?

\section{EMPRESA ANTERIOR:}

EMPRESA ATUAL:

4. A quem se reporta (reportava)?

EMPRESA ANTERIOR:

EMPRESA ATUAL: trabalho?

5. Quais as suas interações com departamentos e com os demais colegas de

\section{EMPRESA ANTERIOR:}

EMPRESA ATUAL: atual?

6. Quais são as competências utilizadas para desempenhar sua função antiga e a

\section{EMPRESA ANTERIOR:}

Habilidades

Atitudes

Conhecimentos

EMPRESA ATUAL:

Habilidades

Atitudes

Conhecimentos

7. Você tem (tinha) autonomia para desempenhar sua função?

\section{EMPRESA ANTERIOR:}

EMPRESA ATUAL:

8. Existe (existia) a figura de um gestor de projetos de design na empresa? Caso negativo, existe (existia) alguma liderança?

EMPRESA ANTERIOR:

EMPRESA ATUAL:

9. Existem (existiam) funções definidas para cada profissional de design?

\section{EMPRESA ANTERIOR:}

EMPRESA ATUAL:

10. Existem (existiam) incentivos de treinamento e desenvolvimento dos funcionários?

EMPRESA ANTERIOR:

EMPRESA ATUAL:

11. Atualmente, com quais profissionais/setores você tem contato (troca informações, apresentação, trabalhos...) nas empresas para as quais presta serviços? Algum deles é terceirizado?

12. Existe alguma equipe de design ou profissional de design nas empresas para as quais você presta serviços?

13. Na opinião do entrevistado, o designer à frente de todo o escritório facilita o processo e o entendimento de projetos de design (situação atual) ou é indiferente? atual?

14. Na visão do entrevistado, quais os pontos fortes e fracos da situação antiga e da 